\title{
El reverso creativo de la alexitimia
}

\author{
Jesús Ramírez-Bermúdez
}

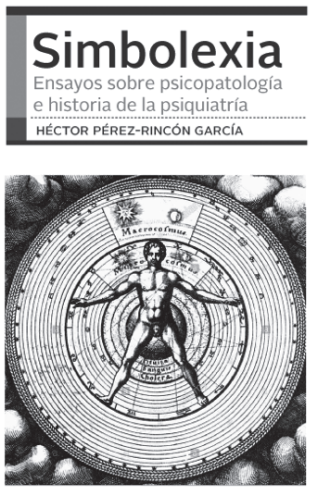

DOI: $10.17711 /$ SM.0185-3325.2018.008
En el campo teórico de la psiquiatría, los años recientes han sido marcados por el surgimiento del paradigma de las neurociencias. Hasta qué punto ocurre en paralelo un ocaso paulatino, pero nunca completo del psicoanálisis, es difícil saberlo. En todo caso, esta progresiva neurologización de la psiquiatría es una moneda de dos caras: por una parte, acerca a la psiquiatría a la lengua común de las ciencias médicas. Pero por otra, el movimiento neurocientífico genera temores de un dominio hegemónico, expresados en muchos campos del saber humano. A lo largo del extenso arco que va del activismo antipsiquiátrico a la filosofía hermenéutica y fenomenológica, surgen críticas a lo que Georges Politzer llamó en 1928 la Gehirnmythologie, "la mitología del cerebro". Ese es precisamente el título de un capítulo en el libro más reciente de Héctor Pérez-Rincón. Este libro surge de una mirada panorámica a los problemas teóricos de la psiquiatría contemporánea, a los dilemas de una profesión médica en la cual convergen tensiones sociales, históricas y epistemológicas de la comunidad humana en su conjunto.

Simbolexia, de Pérez-Rincón, es un libro publicado en 2017 por la Asociación Psiquiátrica Mexicana (Pérez-Rincón, 2017). Se trata de un conjunto de ensayos sobre psicopatología e historia de la psiquiatría. Y en efecto, el libro tiene una doble vocación; por una parte, se trata de una reflexión de gran escala, acerca del conocimiento progresivo de la mente humana y sus problemas médicos. Por otra parte, hay ramificaciones clínicas que surgen de la mirada histórica, y el autor recoge estas ramificaciones para colocarlas en el terreno de la práctica, como si se preguntara qué tan útiles y pertinentes pueden ser hoy algunos conceptos clínicos olvidados durante la "selección natural" de los términos médicos, o atendidos conceptualmente de manera insuficiente en las taxonomías actuales. De esta manera, nos plantea un recorrido por problemas como la acedia, la anhedonia, la melancolía, la celotipia, la algolagnia, la alexisomia, la somatotimia, y, finalmente, la alexitimia. A veces emprende un recorrido histórico por territorios en los cuales es experto, como la escuela de Salpétrière y la invención del psicoanálisis a partir de las zonas oscuras de la neurología. Este tema fue tratado en forma extensa en un libro ya clásico de Pérez-Rincón: El teatro de las histéricas. En otras ocasiones, el autor narra la senda de raíces germánicas que permitió el desarrollo de la neuropsiquiatría centroeuropea y que desemboca en las clasificaciones psiquiátricas de una brillante genealogía de tres generaciones de maestros enlazados por la letra K: Karl Wernicke, Karl Kleist, y Karl Leonhard. Asimismo, discute la pertinencia de las taxonomías herederas de Wernicke, que habrían representado tal vez un contrapeso a las clasificaciones neokraepelinianas de la Asociación Psiquiátrica Americana, de no ser por la muerte prematura de Wernicke, como lo ha narrado German Berrios (2008), y por el colosal accidente histórico que provocó el aislamiento científico de Leonhard, a saber, el muro de Berlín, que dejó a este influyente investigador en el lado oriental de Alemania.

Pérez-Rincón actualiza el pensamiento clínico con esta mirada retrospectiva de largo alcance, y también mediante una crítica a la práctica psiquiátrica. No se trata de la crítica del extranjero que observa un campo de la actividad humana con desconfianza xenofóbica o con una fría hermenéutica de la sospecha. Más bien, hablamos de una crítica que surge al interior del territorio, por un conocedor de las redes prácticas y conceptuales de la psiquiatría. Además, es necesario recordar que el autor es un políglota epistémico: en efecto, su entendimiento del arte, la literatura y las humanidades le permite incorporar conocimientos que surgen de tradiciones milenarias. El resultado de todo esto es un conjunto de apuntes literarios, escritos con una prosa elegante de sensibilidad clásica, que contribuyen a la formación de una filoso- 
fía de la psiquiatría. Lo sabemos: la tradición latinoamericana no ha sido fértil para el surgimiento de auténticos pensadores clínicos. Hay buenos técnicos, por supuesto, algunos científicos brillantes, y suficientes recolectores y organizadores de la información que se genera en el mundo europeo y anglosajón. Pero realmente hay pocos autores con ideas propias. Este libro, entonces, no sólo sigue la estela de su colección previa de ensayos, Eros y Psiqué, sino que forma parte de una constelación intelectual donde la investigación de la creatividad se encuentra con la reflexión médica. Pienso en autores clásicos como Honorio Delgado, en pensadores monumentales como Germán Berrios, ensayistas como Francisco González Crussí, creadores como Bruno Estañol, clínicos como Francisco Alonso-Fernández. Pienso en la inspiración permanente de escritores como Roger Bartra, con su largo recorrido por el canon cultural de la melancolía (Bartra, 2001).

Cuando leí Simbolexia, me pareció que tenía un par de epicentros conceptuales. Por otra parte, el ensayo Defensa e ilustración de la psiquiatría es una articulación coherente de los dilemas éticos y científicos de la profesión psiquiátrica en el mundo contemporáneo. Aborda de frente, y sin eufemismos, la profunda crisis cultural del capitalismo tardío, como algunos pensadores le llaman, y sus consecuencias psicopatológicas, que aparecen en el terreno social como un malestar amorfo en la cultura, como una zona de ebullición que hace posible la formación de adicciones y guerras contra el narcotráfico, violencia en países latinoamericanos, radicalismos ideológicos y religiosos con sus variantes terroristas, trastornos afectivos altamente heterogéneos, y en fin, la aparición del suicidio como una de las causas principales de muerte prevenible en el mundo. Aunque inicialmente los productos de una psiquiatría biológica reduccionista parecían formidables, Pérez-Rincón nos enfrenta a eso que Paul Ricœur llama "ananké": el símbolo de la desilusión. Frente al "desajuste del mundo" diagnosticado por el escritor libanés Amin Maalouf, la medicalización progresiva de la sociedad parece una estrategia rentable para la medicina corporativa y el negocio de la salud, pero totalmente insuficiente, o ciertamente inadecuada, para los fines de una práctica psiquiátrica construida sobre bases éticas. En este contexto, el crecimiento científico provocado por las neurociencias se revela francamente insuficiente, y la pasión reduccionista de algunos colegas psiquiatras, neurobiólogos y neurofilósofos, se revela un tanto dogmática, o ingenua. Este problema se discute en el capítulo La mitología del cerebro, pero la solución que aparece en la punta de la lengua: aumentar la dosis de psicoanálisis en la formación de médicos psiquiatras, no parece despertar un gran entusiasmo en Pérez-Rincón, quien discute la vigencia del legado freudiano en el capítulo Centenario y medio. Lo que sí parece ocupar un lugar en la filosofía psiquiátrica del autor es el concepto más amplio de la transformación de la mente y de las redes neurales mediante la palabra. En el capítulo La psiquiatría: de la neurona a la persona, se discute el efecto de la palabra (terapéutica) en el contexto de la plasticidad cerebral. Este tema se aborda desde otro enfoque en una serie de ensayos que conforman el otro epicentro del libro, y que estudian la relación inversa entre la creatividad y la alexitimia.

El ensayo titulado Cuerpo y palabra en la psiquiatría, aborda la formación progresiva del lenguaje de la subjetividad, eso que hará posible la emergencia de un arte literario, capaz de nombrar lo innombrable del fondo emotivo humano (parafraseando a Hans Georg Gadamer). Pérez-Rincón realiza un análisis fascinante del largo camino para encontrar un lenguaje verbal de la subjetividad, un diccionario colectivo de los estados mentales, y en particular, un léxico emocional. Como punto de partida, expone los trabajos de la escuela de Bruno Snell, quien realiza una asombrosa investigación donde la teoría literaria ofrece materiales indispensables para una ciencia psicológica, que a su vez se verá obligada a incorporar el estudio cultural entre sus asignaturas fundamentales. Me explico: las neurociencias cognitivas utilizan metáforas computacionales para entender lo mental como el resultado de un procesamiento de datos, como una propiedad emergente que surge cuando la información se transforma a través de relevos neuronales progresivos, organizados en forma de circuitos reverberantes altamente jerarquizados. $\mathrm{Al}$ fondo de esta visión, plenamente vigente, se encuentra la metáfora de la máquina: del cerebro como "máquina" viviente capaz de producir, mediante mecanismos de transducción, no sólo las funciones mentales, sino de hecho las experiencias subjetivas y toda forma de conciencia de la que seamos capaces de hablar. ¿Se trata de un proceso natural? ¿Podemos hablar de una mecánica neural de la subjetividad, como lo plantean muchos neurofilósofos en la corriente conocida como materialismo eliminativista? ¿Cuál es el papel de la cultura en la formación de la subjetividad? Para seguir a Bruno Snell y a Héctor Pérez-Rincón en su búsqueda de una respuesta, debemos remontarnos a un tiempo anterior a la era cristiana, anterior incluso a la filosofía griega, al budismo, al taoísmo y al pensamiento de Confucio. Si estudiamos la poética de La Iliada y La Odisea, piedras fundacionales indiscutibles de la cultura occidental, podremos observar que "todo el relato homérico describe esencialmente conductas en las que está ausente el componente interior, propiamente psicológico, que permanece sin expresarse y no por motivos estéticos, $[\ldots]$ sino porque no existían todavía los medios lingüísticos adaptados para expresar la interioridad. Sus descripciones de cualidades de personalidad se hacen siempre a través de descripciones corporales" (Pérez-Rincón, 2017). Aunque se desconoce la edad exacta de estas obras literarias, la mayoría de los expertos coinciden en que provienen del siglo VIII antes de Cristo. Podemos decir que hace unos 2700 años, el poeta más célebre de la antigüedad no disponía de un léxico suficiente para comunicar los estados mentales de sus personajes (los héroes y villanos de la guerra de Troya). No hay un acuerdo definitivo en la lingüística contemporánea con respecto a la propuesta de Noam Chomsky, según la cual hay una gramática universal al fondo de todas las lenguas humanas, a pesar de su casi interminable diversidad. Pero aún en el caso de que esta gramática universal exista, debemos aceptar que hay una evolución histórica de nuestras lenguas. El rastro dejado por la 
Ilíada nos muestra que en tiempos de Homero había un léxico bien desarrollado para describir experiencias sensoriales, así como las acciones de los seres vivos: su desplazamiento, sus encuentros, incluso su conducta verbal. ¿Pero cómo se describían, entonces, los estados mentales subjetivos menos accesibles a los órganos de los sentidos? Me refiero a las experiencias emocionales, por ejemplo. Héctor Pérez-Rincón nos informa que esto sucedía mediante un proceso de metaforización. Es decir, el uso de frases referidas a propiedades físicas captadas por los órganos de los sentidos (por ejemplo "un pie rápido") señala también cualidades de la personalidad, estilos de comportamiento, que a su vez denotan pautas psicológicas. Estas metáforas nombran en forma indirecta la cualidad psicológica. "Un pie rápido" puede usarse para describir un personaje ágil, con tiempos de reacción cortos, con buenos reflejos, dispuesto para la acción. Otras metáforas homéricas útiles para esta discusión, citadas por el autor, son las siguientes: "un ojo despierto", "una buena cabeza". La primera describe un objeto real, sensible, el ojo, que se convierte en metáfora del estado de alerta, la atención y la consciencia, en virtud del adjetivo "despierto". El adjetivo, aplicado al objeto correcto, sirve para anunciar la cualidad mental que sólo será nombrada varios siglos después. "Una buena cabeza" describe probablemente a un hombre sensato, razonable, o tal vez con atributos de generosidad moral. De esta manera, la cultura de la Antigüedad, en la civilización heterogénea del Mediterráneo (pero podemos suponer que existieron procesos similares en otras civilizaciones) "inicia un lento proceso de metaforización que a partir de la descripción y experiencia corporales dará lugar a la construcción de un nivel diferente cada vez más autónomo, en lo que se refiere a su percepción, que es el de lo mental."

Un primer ensayo en el largo camino hacia la reflexión subjetiva se da en el monólogo de Odiseo "Soporta, corazón", en el cual, la expresión verbal de una pequeña crisis en la toma de decisiones significa dos cosas: la posibilidad de aplazar la acción y el surgimiento de una verbalización de estados subjetivos que no son meras representaciones sensoriales, y no son tampoco indicaciones verbales dirigidas a los demás. Cuando el sujeto habla consigo mismo, se crea mediante el recurso del lenguaje un nuevo peldaño en la conciencia. Esto hará posible el surgimiento de la reflexión introspectiva, que dará lugar a la confesión religiosa, y más tarde, a la psicoterapia. Pero también, el registro verbal del monólogo es ancestro en muchos sentidos del análisis filosófico, basado ante todo en recursos metacognitivos y específicamente metalingüísticos. En el plano de la literatura, Pérez-Rincón considera que la complejidad lingüística creciente favorece el desarrollo de una conciencia de la individualidad, la gestión del libre albedrío, y el sentido de responsabilidad moral. "En el orden y el sentido de las vivencias humanas se comienza a ver no solamente una repetida intervención de los dioses, sino la acción de fuerzas interiores" (Pérez-Rincón, 2017). Más aún, esta evolución cultural catalizada por el lenguaje de la subjetividad culmina en "la rebelión contra los dioses y el destino que observamos en la lírica y la tragedia" (Pérez-Rincón, 2017). En el plano histórico, este proceso alcanzó un alto grado de sofisticación en un lapso no mayor a tres siglos: en el siglo $\mathrm{V}$ antes de Cristo, en Atenas, asistimos a un clímax en el desarrollo de la literatura, la historia y la filosofía: el metalenguaje alcanza niveles formidables de abstracción en la obra de Platón o Aristóteles, por mencionar solamente los autores más universales. En el ensayo La disociación de la personalidad y el otro yo proustiano, Pérez-Rincón avanza más de dos milenios para exponer los alcances más sublimes de la literatura que comunica los pormenores de la vida subjetiva. Me refiero a esa "catedral de papel" novelística, conocida en conjunto como En busca del tiempo perdido, de Marcel Proust. Leer esta obra, nos dice Pérez-Rincón (2017), "debería ser una ascesis obligatoria para quienes deben estar a la escucha de la mente en todos sus estados." En otras palabras, un especialista en la medicina de la psique, un psiquiatra, debería conocer esta obra para explorar a profundidad, como Proust, la "fenomenología de la rememoración súbita e involuntaria de una atmósfera emocional completa, a partir de la percepción de un estímulo que pone en contacto dos momentos diferentes" (Pérez-Rincón, 2017). Esta fenomenología literaria tiene un gran interés clínico, porque expone en forma detallada los acontecimientos subjetivos que se despliegan durante una entrevista a profundidad, o durante la conversación psicoterapéutica. Pero este estudio de la rememoración, que es una respuesta moderna al legendario ensayo de Aristóteles acerca de la mneme y la anamnesis, no es la única aportación de Proust a la comprensión de la vida subjetiva: en sus novelas se estudia también, por un lado, "el amor bajo todas sus formas, con sus peculiaridades y peligros, y por el otro, la función hípnica y en menor medida la actividad onírica, los estados hipnagógicos e hipnopómpicos, la estructuración y la disolución de la conciencia, y el efecto que los fármacos tienen sobre ese proceso" (Pérez-Rincón, 2017). A juicio de nuestro autor, En busca del tiempo perdido realiza una verdadera transvertebración entre psiquiatría y literatura. Este proceso capaz de articular verbalmente las experiencias propias de los estados oníricos, de la evocación, de la imaginación, alcanza su mayor expresión en la creación literaria, y él dedica muchas páginas de Simbolexia a discutir los mecanismos que hacen posible la síntesis creadora.

En el ensayo Los avatares de la palabra y el cuerpo, el autor introduce un neologismo: "simbolexia", con el cual Klaus D. Hoppe ha planteado en su momento la hipótesis de un "delicado proceso neural" para explicar el misterioso fenómeno de la creatividad (Pérez-Rincón, 2017), un resultado siempre sorprendente de la colaboración establecida, según Octavio Paz, entre la mitad oscura y la mitad luminosa del creador. Si la metáfora de Paz parece estar influida por los modelos psicoanalíticos y el arte surrealista, el neologismo de Klauss D. Hoppe sintetiza una conceptualización neurocientífica: la creatividad surge mediante un proceso de comunicación interhemisférica. Pero ¿a qué se refiere exactamente Pérez-Rincón cuando usa el término "creatividad"? La descripción que utiliza para caracterizar el pensamiento creativo 
proviene de Peter Emanuel Sifneos (1988), un distinguido profesor de psiquiatría de Harvard:

La persona creativa utiliza al máximo las capacidades de ambos hemisferios cerebrales [...] Debe ser original, imaginativa, sensitiva, capaz de descubrir las conexiones ocultas, tolerar los conocimientos paradójicos, usar la intuición y poseer la capacidad de sintetizar experiencias opuestas e inéditas en un todo significativo. La persona creativa puede teorizar, inventar, abrir su mente a las sensaciones que recibe, captar nuevos caminos para contemplar la complejidad, y prever nuevas vías para resolver diversos y contradictorios puntos de vista. $\mathrm{Al}$ mezclar estos factores una persona creativa puede producir nuevas ideas y nuevas teorías y puede usar un lenguaje original para expresarlas, hasta crear nuevas e interesantes palabras.

A mi juicio, la descripción de Sifneos se refiere en mayor grado a las formas verbales de la creatividad, como las que se despliegan en la literatura, la filosofía, y en otras ramas de la innovación conceptual. Pero las actividades artísticas "no verbales" también requieren procesos de simbolización, así como códigos semióticos capaces de estructurar las experiencias subjetivas, con el fin de hacerlas inteligibles y comunicables para los demás. Esto sucede mediante la selección de signos y su secuenciación sintáctica; en la creatividad matemática, en la música o la coreografía. El uso de códigos semióticos permite un intercambio altamente estructurado y renovador entre las redes neurales del individuo creativo y las redes culturales colectivas. Esto establece canales para la conectividad entre el individuo y su entorno humano, que pueden apreciarse mejor bajo la metáfora neurofisiológica de los circuitos reverberantes de retroalimentación positiva: el individuo creativo enriquece su tejido social y el tejido social lo enriquece a él. Pero ¿podemos decir algo acerca de la conectividad cerebral del individuo creativo? La clave para contestar esta pregunta es la alexitimia. En la formulación de Pérez-Rincón, este problema clínico cobra una relevancia teórica inesperada.

Un antecedente clínico necesario para entender los trastornos de la simbolización es el concepto de somatización, usado inicialmente por Wilhelm Steckel a principios del siglo XX, para aludir a conflictos que no son verbalizados y que sólo entran en el terreno de la conciencia y de la comunicación como quejas somáticas. Durante la segunda mitad del siglo XX, mientras atendía pacientes somatizadores, Peter Emanuel Sifneos acuñó el término "alexitimia" para referirse a personas con dificultades para la verbalización de las emociones. Pérez-Rincón nos presenta los siguientes elementos para la formulación actual de este constructo clínico: a) hay dificultad para identificar y comunicar estados emocionales, b) el paciente no distingue claramente entre emociones y sensaciones corporales, c) hay pobreza en la capacidad de simbolización, lo cual se expresa en el déficit de fantasías y capacidades imaginativas, y d) el paciente prefiere enfocarse en acontecimientos externos con respecto a las experiencias internas. Debido a las deficiencias en la simbolización, la fantasía y la imaginación, la alexitimia puede funcionar como un modelo opuesto a la creatividad. Y un hecho neuropsiquiá- trico viene a la luz: la condición alexitímica se presenta de manera muy evidente en pacientes que han sufrido una comisurotomía, es decir, una interrupción quirúrgica del cuerpo calloso. En tales condiciones, la información procesada por el hemisferio derecho, formada por patrones visoespaciales e imágenes con alta carga emocional, no logra viajar al hemisferio izquierdo, donde debería segmentarse para ser ordenada secuencialmente, tal y como lo exige el formato verbal. En otras palabras, las experiencias preverbales pero altamente emotivas procesadas por el hemisferio derecho deberán articularse mediante una sintaxis administrada por el hemisferio izquierdo. Esto pone de relieve que la verbalización emocional requiere, desde el punto de vista neurobiológico, una conectividad cerebral, entre los módulos lingüísticos del hemisferio izquierdo, localizados principalmente en las áreas de Broca y Wernicke, y las otras regiones cerebrales en las cuales se procesan emociones: regiones frontotemporales del hemisferio derecho, y en mayor medida, todo el sistema límbico. Desde la perspectiva neurocientífica, la verbalización de las emociones significa una transferencia de datos en conexiones cortico-límbicas y cortico-corticales. Probablemente, ocurre también una transducción, es decir, una transformación del tipo de información durante el paso de un módulo cerebral a otro. Todo esto, que falla en el sujeto alexitímico, podría encontrar su modo de operación más eficiente en el fenómeno de la simbolexia, que nos permite entender la creatividad como resultado de una transformación transcallosa, cortico-cortical y cortico-límbica de la información, que permite la generación de nuevas síntesis conceptuales, de innovaciones semánticas. El círculo virtuoso se completa cuando reconocemos la capacidad cortical para el uso de códigos semióticos, y de secuencias motoras. Esto hace posible la comunicación de las ideas creativas y la generación de efectos de realidad mediante el discurso y la actividad práxica.

Al final del recorrido por Simbolexia, nos queda la sensación de haber asistido a una puesta en escena de ideas que provienen de la literatura, por una parte, y por otra parte de la historia de la psiquiatría. Esta interlocución prudente ha sido capaz de señalar los planos de un proyecto futuro para la transvertebración de la psiquiatría y la literatura. Y lo que surge de esta síntesis es una filosofía renovada para la práctica clínica, para esa clase de medicina psiquiátrica que vamos a necesitar durante los "desajustes del mundo" contemporáneo.

\section{REFERENCIAS}

Bartra, R. (2001). Cultura y melancolía. Las enfermedades del alma en la España del siglo de oro. Barcelona: Anagrama.

Berrios, G. (2008). La historia de los síntomas de los trastornos mentales. Ciudad de México: Fondo de Cultura Económica.

Pérez-Rincón, H. (2017). Simbolexia. Ensayos sobre psicopatología e historia de la psiquiatría. Ciudad de México: Asociación Psiquiátrica Mexicana.

Sifneos, P. E. (1988). Alexithymia and its relationship to hemispheric specialization, affect, and creativity. Psychiatric Clinics of North America, 11, 287-291. 